\title{
Minimum Heart Rate by Electrocardiogram
}

National Cancer Institute

\section{Source}

National Cancer Institute. Minimum Heart Rate by Electrocardiogram. NCI Thesaurus.

Code C119258.

An electrocardiographic measurement of the minimum number of depolarisations of a specific region of the heart, most often the ventricles, recorded during a specified, extended period of time, and usually expressed in beats per minute. 